\title{
Heterogeneity in urology teaching curricula among Canadian urology residency programs
}

\author{
Uday Mann, MD; Ryan Ramjiawan, MD; Jasmir G. Nayak, MD, FRCSC; Premal Patel, MD,
} FRCSC

${ }^{1}$ Section of Urology, Department of Surgery, University of Manitoba, Winnipeg, MB, Canada

Acknowledgements: The authors would like to sincerely thank all of the residency program directors for participating in this survey.

Cite as: Can Urol Assoc J 2020 July 17; Epub ahead of print. http://dx.doi.org/10.5489/cuaj.6659

Published online July 17, 2020

$* * *$

\begin{abstract}
Introduction: Postgraduate education is transitioning to a competency-based curriculum in an effort to standardize the quality of graduating trainees. The learning experiences and opportunities in each institution are likely variable, as no standard exists regarding the teaching curriculum offered through residency. The objective of this study is to examine the various teaching curricula among different Canadian urology residency programs and to identify which teaching modalities are prioritized by program directors.

Methods: A 10-question anonymous survey was sent electronically to program directors at all 12 urology residency programs across Canada. Questions were designed to quantify the time allotted for teaching and to assess the various teaching session types prioritized by programs to ensure the successful training of their graduates. We assessed each program's perceived value of written exams, oral exams, didactic teaching session, and simulation sessions. Responses were assessed using a Likert-scale and a ranking format. Descriptive statistics were performed.

Results: Overall survey response rate from residency program directors was 75\% (9/12). Sixtyseven percent of programs designated one day of teaching per week, whereas 33\% split resident teaching over two days. Review of chapters directly from Campbell-Walsh Urology textbook were deemed the most valuable teaching session. Practice oral exams were also prioritized, whereas most programs felt that simulation labs contributed the least to residency education. All programs included review of the core urology textbook in their weekly teaching, while only $67 \%$ of programs included faculty-led didactic sessions and case presentations. Forty-four percent of
\end{abstract}


programs included resident-led didactic sessions. Practice oral exams and simulation labs were the least commonly included teaching modalities.

Conclusions: Although most program directors prioritize the review of chapters in the core urology textbook, we found significant heterogeneity in the teaching sessions prioritized and offered in current urology residency curricula. As we move to standardize the quality of graduating trainees, understanding the impact of variable educational opportunities on residency training may become increasingly important.

\section{Introduction}

Canadian post-graduate medical training is actively transitioning from a traditional "time-spent" method of training to a "competency-based" medical education (CBME) ${ }^{1-7}$ In fact, Canadian Urology programs have been early adopters, having introduced the CBME stream residents in 2018. The traditional "time-spent" model of residency was first formalized by Osler, Welch and Halsted over 100 years ago. The requirements of such a residency included "a fixed period of time for training, structured educational content, actual experience with patients, escalating responsibility for patient care during training, and a period of supervised practice after formal training". ${ }^{8}$ Since then, national standards have been imposed upon residency programs and trainees are required to write board examinations to prove their knowledge expertise to practice medicine independently. However, recent studies have shown that contemporary surgical trainees have significantly reduced learning opportunities as compared to their predecessors due to new regulations on trainee working hours, increasing pressures for operating room efficiency, and patient safety initiatives. ${ }^{9-15}$ Additionally, recently graduated trainees also expressed a lack of confidence in performing several surgical procedures independently. ${ }^{14,16}$ Given these changes in the healthcare system, many overseeing regulatory bodies such as the Accreditation Council for Graduate Medical Education (ACGME) and The Royal College of Physicians and Surgeons of Canada (RCPSC) have responded by transitioning to a CBME approach, with the goal being to standardize the quality of graduating trainees.

The transition towards a competency-by-design format for urology residency programs in Canada began in 2018. Rourke et al. surveyed practicing urologists in Canada and found consensus on 30 procedures that were felt to comprise a core surgical curriculum in urology. ${ }^{3}$ The Royal College has since put forth a list of core competencies for urology programs to assess resident progress throughout their training. Though this list of core competencies aims to standardize the quality of all graduating residents, it does not provide urology residency programs with specific urology curricula. Despite demonstrating clinical competence via CBME, all trainees must still exhibit expertise of urologic knowledge by completing certifying 
examinations such as the written/oral Royal College examinations. Although all trainees must successfully complete the same Royal College examinations to become certified for independent practice, currently there is no nationally unified curriculum for urology residency programs.

Our study aims to evaluate the variability in residency teaching curricula across Canadian urology programs and to determine which teaching modalities are prioritized by program directors for preparing residents for Royal College examinations. We hypothesized that most Canadian urology program directors would assign value to similar teaching modalities yet will have variability in how these sessions are utilized in preparation for the Royal College certifying examination.

\section{Methods}

Ethics approval was obtained from the Research Ethics Board at the University of Manitoba. A 10-question anonymous online survey (Appendix 1) was distributed to all 12 urology residency program directors across Canada via email in the fall of 2019.

The survey consisted of 10 questions in English. One question ascertained the geographic location of the residency program to ensure that we had good representation of the various residency programs. Two questions inquired about the subjective importance placed on different teaching modalities by different program directors. This was done using ranking and Likert-scale questions. Three questions examined the structure of weekly academic activities by the quantifying the number of days and the number of hours per teaching modality. We inquired into the number of annual practice examinations and the number of weeks for protected study time to Chief residents. Two questions utilized a Likert-scale to examine the utilization of different simulation courses (robotic, endoscopic, laparoscopic) for trainees. Lastly, we inquired whether residency programs implemented changes to their academic curricula based on the implementation of CBD and offered the respondents a chance to comment on any changes their programs were undergoing. Descriptive statistics were used to summarize and analyze the findings.

\section{Results}

The survey response rate was $75 \%(9 / 12)$ with representation from all of the regions in Canada (Table 1).

Respondents identified chapter reviews of Campbell-Walsh Urology textbook to be the most valuable teaching modality to resident education with respect to preparation of the Royal College examinations (average rank 1.89) (Table 2). This was followed by resident OSCEs (2.67), review of guidelines (3.33), and case presentations (4.22). The teaching modalities that were felt to be of least importance were faculty-led seminars (4.78), resident-led seminars (5.00), and simulation labs (6.11). 
When asked to quantify their level of agreement on whether specific teaching modalities were valuable to resident education, chapter reviews of Campbell-Walsh Urology textbook were felt to be of importance as $55.6 \%$ of respondents "strongly agreed", while the remaining $44.4 \%$ indicated that they "agreed" with the statement "Campbell's chapter reviews are valuable to resident teaching". Reviews of guidelines were also felt to be similarly important, with $55.6 \%$ of program directors "strongly agreeing" and $44.4 \%$ "agreeing" that guideline reviews were valuable to resident teaching. The remainder of teaching modalities included case presentations, faculty-led seminars, resident-led seminars, simulation labs, and multi-disciplinary rounds. These remaining modalities had a wide heterogeneity of answers, with ranges of $0-33.3 \%$ of respondents "strongly agreeing", 44.4-88.9\% of respondents "agreeing", and $0-33.3 \%$ of respondents "neutral" with the statements that these teaching modalities are valuable to resident teaching (Figure 1).

During the academic year, three programs (33.3\%) scheduled didactic teaching activities two days each week, while the remaining six programs $(66.7 \%)$ scheduled didactic teaching activities one day each week. 100\% of programs included chapter reviews of Campbell-Walsh Urology textbook in their weekly structured resident teaching curricula. The next most commonly included teaching modality was multi-disciplinary rounds, with $77.8 \%$ of programs including this modality in their curricula. Following this, case presentations and faculty-led seminars were included in $66.7 \%$ of programs' weekly curricula. The remaining teaching modalities including resident-led seminars, review of guidelines, resident OSCEs, and simulation labs were included in weekly curricula amongst $11.1-44.4 \%$ of programs (see figure 2).

The majority of programs (66.7\%) spent one hour per week on chapter reviews of Campbell-Walsh Urology textbook, while $22.2 \%$ spent two hours per week, and $11.1 \%$ spent three hours per week. The remainder of the hourly breakdown per teaching modality can be seen in figure 3.

The survey identified that $44.4 \%$ of programs offered their PGY-5 residents five or more weeks of "protected study time" in order to prepare for their Royal College exams. $22.2 \%$ offered four weeks and $33.3 \%$ offered two weeks of protected study time. Inquiring about resident assessments with formal OSCEs or written examinations revealed a large amount of heterogeneity within residency programs. Practice written exams were also variably offered, ranging from $5 \mathrm{x}$ per year to less than once per year. Similar variations were seen when inquiring about the number of OSCEs yearly, and the frequency in which trainees are sent to an outside institution for additional OSCE preparation (see figure 4).

Regarding simulation courses, $88.9 \%$ of respondents stated that their program offers or supports residents for laparoscopic simulation courses. $77.8 \%$ of programs offer or support residents for endoscopic simulation courses, while only $33.3 \%$ of programs include robotic 
simulation courses (figure 5). A large degree of heterogeneity was seen when assessing the frequency of these simulation courses (see figure 6).

When asked whether their program is changing the academic curriculum based on the implementation of CBME, three (33.3\%) of the respondents indicated that changes were being made but we did not receive granular feedback into details.

\section{Discussion}

As post-graduate medical education transitions towards a competency-based format, a majority of the focus for surgical disciplines has been on identifying core surgical procedures to ensure that trainees are competent to complete surgical procedures independently. ${ }^{2-5,7,17}$ Despite the intentions of CBME being to standardize the quality of graduating residents, there remains no consensus on urology teaching curricula that residency programs should offer their trainees. In order to become certified as independent practitioners, trainees must exhibit expertise in subject knowledge, which is formally examined by completing board examinations (Royal College examinations in Canada). Currently, there is no consensus amongst different urology residency programs on the type of curriculum to be utilized to best ensure resident learning and success on the board examinations. This survey aimed to assess urology curricula at different urology residency programs in Canada and found that though there was a relative consensus amongst program directors on which teaching modalities they subjectively valued, yet there was a large degree of heterogeneity in which modalities were offered at different residency programs.

The survey found that though chapter reviews of Campbell-Walsh Urology textbook averaged the highest rank in terms of importance to resident education in preparation of the Royal College examinations, there was a wide range of ranks assigned by the program directors. One of the program directors ranked the chapter reviews to be the fifth most important. Given this large range in ranking, it is apparent that though most program directors value chapter reviews of Campbell-Walsh Urology textbook for resident learning, this is not a shared sentiment amongst every program director. This discrepancy in subjective importance was most pronounced for "faculty-led seminars," with a range of ranking from most important to the least important. Conversely, there was general consensus amongst program directors that simulation labs were not important for resident learning in preparing for the Royal College examinations. This result is unsurprising because the question specifically pertained to preparing residents for a board examination and not for technical skills.

As expected, chapter reviews of Campbell-Walsh urology textbook were included in the structured resident teaching in every residency program. Interestingly, despite ranking second in terms of importance to resident education, only $22 \%$ of program directors stated that they include resident OSCEs in their weekly structured resident teaching. A possible explanation for this may be due to the fact that arranging OSCEs is time and resource intensive, an endeavour which may 
not be feasible for every residency program. A similar pattern was seen with guideline reviews, which ranked third in terms of importance but were only included in 33\% of program's weekly structured resident teaching. Another curious finding was that case presentations, faculty-led seminars, and resident-led seminars all ranked lower in terms of importance compared to OSCEs and guideline reviews, yet these modalities were included in $44-67 \%$ of program's weekly structured resident teaching. A possible explanation for this may be due to different curricula requirements at each residency program. For example, residency programs may require each resident to present at the weekly rounds a certain number of times per academic year.

Additionally, different academic centres may have different requirements of their faculty to engage in academic activities. Furthermore, different institutions may require the faculty or resident seminars to include chapter reviews of the Campbell-Walsh urology textbook, which could have led to discrepancies.

The results of this survey are interesting when compared to the 2017 study by Skinner et al. ${ }^{18}$ Skinner et al. examined the study habits of Canadian urology residents and found that while there is no single dominant resource for studying for junior residents, the most dominant resources for studying for PGY-5 residents preparing for the Royal College exams consisted of CampbellWalsh urology textbook, AUA/CUA guideline reviews, and old study notes. ${ }^{18}$ The fact that many PGY-5 residents ranked review of Campbell-Walsh urology textbook and guideline reviews highly is reassuring because the results of our survey suggest that these teaching modalities are also highly valued by most program directors. However, more program directors may want to consider allotting time for guideline reviews, as currently only $33 \%$ of programs include them in their weekly structured resident teaching.

More heterogeneity was identified when the survey inquired about "protected study time" for the PGY-5 residents in preparation for the Royal College examinations. Although all programs offered their trainees protected time off clinical duties, this ranged from two weeks to five or more weeks at various programs. Given this wide range in protected study time, it could be extrapolated that some trainees may be better prepared for the examinations because they were provided with more protected study time. However, the relationship between the amount of protected time permitted and exam preparedness is not truly known but is likely to have limited effect given the countless hours over many months required for exam success.

One possible theory to account for the heterogeneity seen in this survey is that different programs may have different approaches to delivering the same content. For example, one program may prefer to deliver content via faculty-led presentations, whereas a second program may prefer resident-led presentations to deliver the same content. Unfortunately, the current literature is lacking data on which teaching modalities are superior for resident teaching and ultimately, success on board examinations. Although there are certainly many different ways that trainees learn, currently the Royal College examinations are the only method of examining the 
knowledge of Canadian urology residents. Going forward, emphasis should be placed into identifying which teaching modalities would maximally benefit resident learning.

Recent research into medical education has focused on the theory of test-enhanced learning. The theory of test-enhanced learning is that frequent yet spaced out examinations promote better retention of information "since each test is a chance for further retrieval practice and theoretically strengthens the connections between concepts." ${ }^{" 19,20}$ Provided this, the finding that there is large degree of heterogeneity in the number of yearly written examinations and OSCEs that residency programs offer to their residents furthers the call towards unifying a national curriculum. It can be hypothesized that programs that offer their trainees with more frequent testing may perform better on the Royal College examinations due to being provided more opportunities to develop their "examsmanship" skills.

Finally, provided that the focus of CBME is on technical skills, the survey aimed to quantify if and how frequently simulation courses aimed to develop technical skills were offered to trainees. Although most programs offered laparoscopic and endoscopic simulation courses, there was a wide variation in how frequently the courses were offered. Once again, this heterogeneity between the opportunities offered to trainees at different residency programs raises the question regarding the utility of a nation-wide urology curriculum.

The findings of this study must be considered in the context of its limitations. Firstly, the response rate was relatively low and the findings may not be fully representative. This may in part be due to the fact that the survey was only available in English. Secondly, the survey did not undergo test-retest validity. However, the purpose of the study was to obtain a snapshot of Canadian Urology teaching programs. Lastly, our survey was aimed towards the program directors who would have an intimate knowledge of the teaching curriculum. There is a risk that the results obtained may be different if current residents or recent graduates were included. Nonetheless, the findings represent the first evaluation of Canadian urology residency teaching curricula and may serve as a guide for programs considering altering their teaching structure.

\section{Conclusions}

Canadian urology program directors value similar resources for residency training, yet there is large variability in the utilization of resources amongst individual residency programs. As we transition into the competency-based era of post-graduate medical education, understanding the impact of various educational resources and opportunities will become increasingly important. Though the results of the survey lend support for a nationally unified teaching curriculum, more investigation is required to identify which teaching modalities would maximally benefit resident learning. 


\section{References}

1. Bhatti NI, Cummings CW. Viewpoint: Competency in Surgical Residency Training: Defining and Raising the Bar. Acad Med 2007; 82:569-73.

2. Nguyen VT, Losee JE. Time- versus Competency-Based Residency Training. Plast Reconstr Surg 2016; 138:527-31. doi:10.1097/PRS.0000000000002407.

3. Rourke KF, MacNeily AE. Mapping a competency-based surgical curriculum in urology: Agreement (and discrepancies) in the Canadian national opinion. CUAJ 2016;10:161-6. doi:10.5489/cuaj.3699.

4. Lutz K, Yazdani A, Ross D. From Time-Based to Competency-Based Standards_Core Transitional Competencies in Plastic Surgery. J Surg Educ 2015; 72:228-34. doi: 10.1016/j.jsurg.2014.08.013.

5. Nousiainen MT, Polina M, Melissa H, et al. Eight-year outcomes of a competency-based residency training program in orthopedic surgery. Med Teach 2018;40:1042-54. doi:10.1080/0142159X.2017.1421751.

6. Wagner N, Fahim C, Dunn K, Reid D, Sonnadara RR. Otolaryngology residency education: a scoping review on the shift towards competency-based medical education. Clin Otolaryngol 2016; 42:564-72. doi:10.1111/coa.12772.

7. Szasz P, Louridas M, Harris KA, Aggarwal R, Grantcharov TP. Assessing Technical Competence in Surgical Trainees. Ann Surg 2015; 261:1046-55. doi:10.1097/SLA.0000000000000866.

8. Long DM. Competency-based Residency Training: The Next Advance in Graduate Medical Education. Acad Med 2000; 75:1178-83.

9. Scally CP, Reames BN, Teman NR, Fritze DM, Minter RM, Gauger PG. Preserving Operative Volume in the Setting of the 2011 ACGME Duty Hour Regulations. J Surg Educ 2014; 71:580-6. doi: https://doi.org/10.1016/j.jsurg.2014.01.004.

10. Reznick R, MacRae H. Teaching Surgical Skills — Changes in the Wind. N Engl J Med 2006; 355:2664-9.

11. Sonnadara RR, Mui C, Mcqueen S, et al. Reflections on Competency-Based Education and Training for Surgical Residents. J Surg Educ 2014; 71:151-8.

12. Weatherby BA, Rudd JN, Ervin TB, Stafford PR, Norris BL. The effect of resident work hour regulations on orthopaedic surgical education. J Surg Orthop Adv 2007; 16:19-22.

13. Short AC, Rogers SJ, Magann EF, Rieg TS, Shapiro A, Morrison JC. The 80-hour workweek restriction: How are OB/GYN resident procedure numbers affected? J Matern Fetal Neonatal Med 2009; 19:791-6. doi:10.1080/14767050601023277.

14. Bell RH, Biester TW, Tabuenca AS, et al. Operative Experience of Residents in US General Surgery Programs: A Gap Between Expectation and Experience. Ann Surg 2009; 249:719-24.

15. Harris JD, Staheli G, LeClere L, Andersone D, McCormick F. What Effects Have Resident Work-hour Changes Had on Education, Quality of Life, and Safety? A Systematic Review. Clin Orthop Relat Res 2014;473:1600-8. doi:10.1007/s11999-0143968-0. 
16. Okhunov Z, Safiullah S, Patel R, et al. Evaluation of Urology Residency Training and Perceived Resident Abilities in the United States. J Surg Educ 2019; 74:936-48. doi: 10.1016/j.jsurg.2019.02.002.

17. Knox ADC, Gilardino MS, Kasten SJ, Warren RJ, Anastakis DJ. Competency-Based Medical Education for Plastic Surgery. Plast Reconstr Surg 2014; 133:702e-710e. doi:10.1097/PRS.0000000000000082.

18. Skinner TAA, Ho L, Touma NJ. Study habits of Canadian urology residents: Implications for development of a competence by design curriculum. CUAJ 2017; 11:83-85. doi:10.5489/cuaj.4132.

19. Larsen DP, Butler AC, Roediger HL III. Test-enhanced learning in medical education. Med Educ 2008; 42:959-966. doi:10.1111/j.1365-2923.2008.03124. x.

20. Schiff K, Williams DJ, Pardhan A, Preyra I, Li S-A, Chan T. Resident Development via Progress Testing and Test-Marking: An Innovation and Program Evaluation. Cureus 2017;9: e992. doi:10.7759/cureus.992. 


\section{Figures and Tables}

Fig 1. To what extent do you agree that the teaching modality is valuable to resident education and preparation for the Royal College Certifying Exam (\%)?

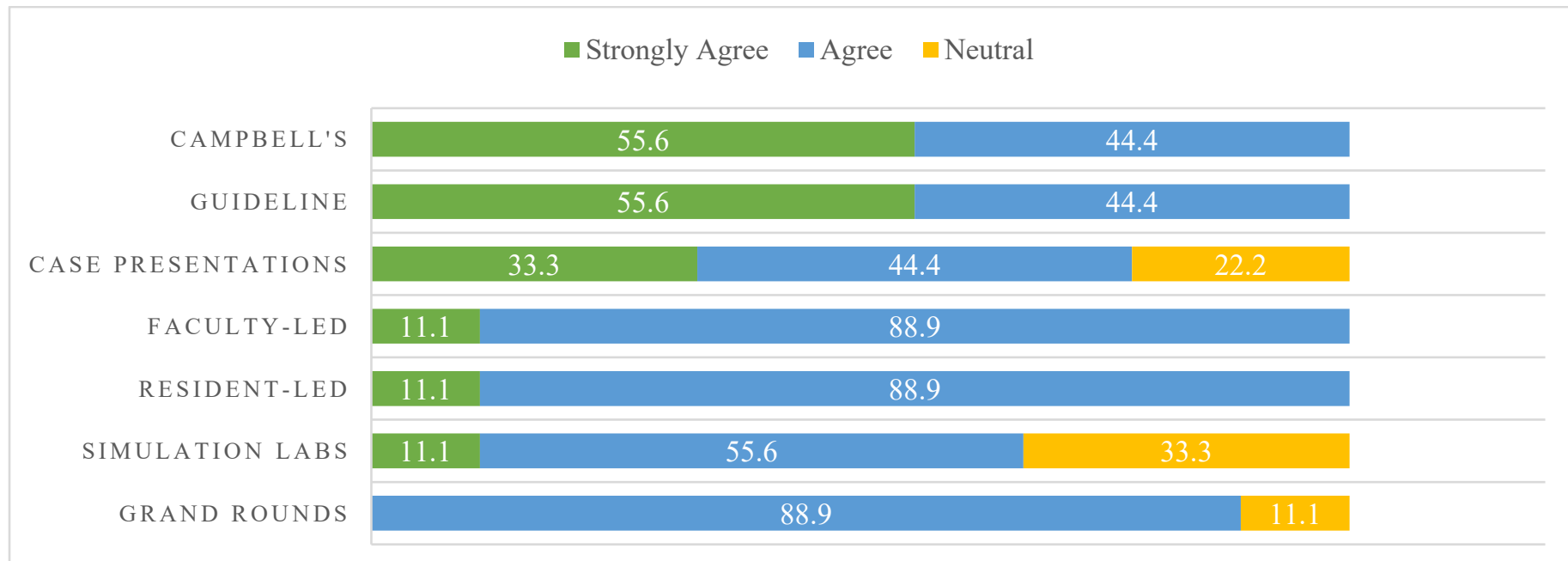

Fig 2. In a typical week, the structured resident teaching includes (\%):

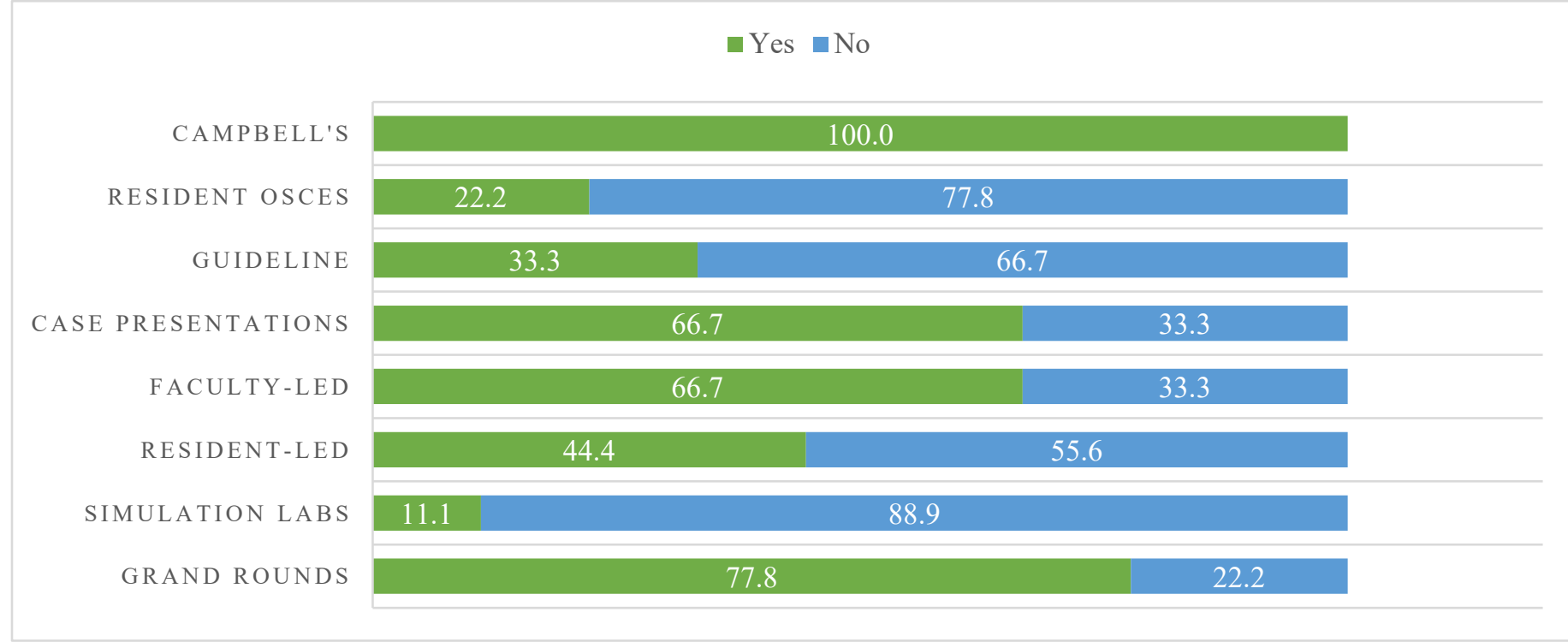


Fig 3. In a typical week, how many teaching hours are devoted to (\%):

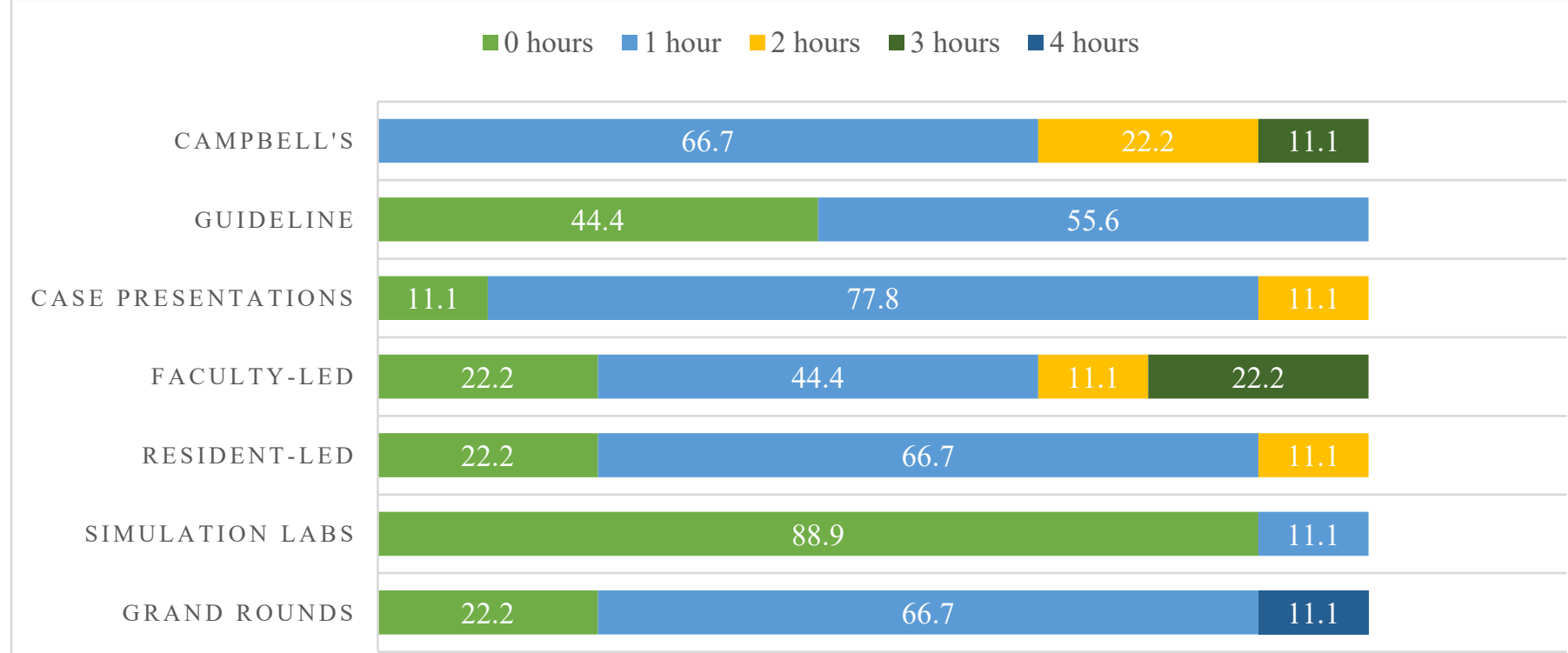

Fig 4. In a typical year, how many $\mathrm{X}$ does your program offer to the trainees (\%)?

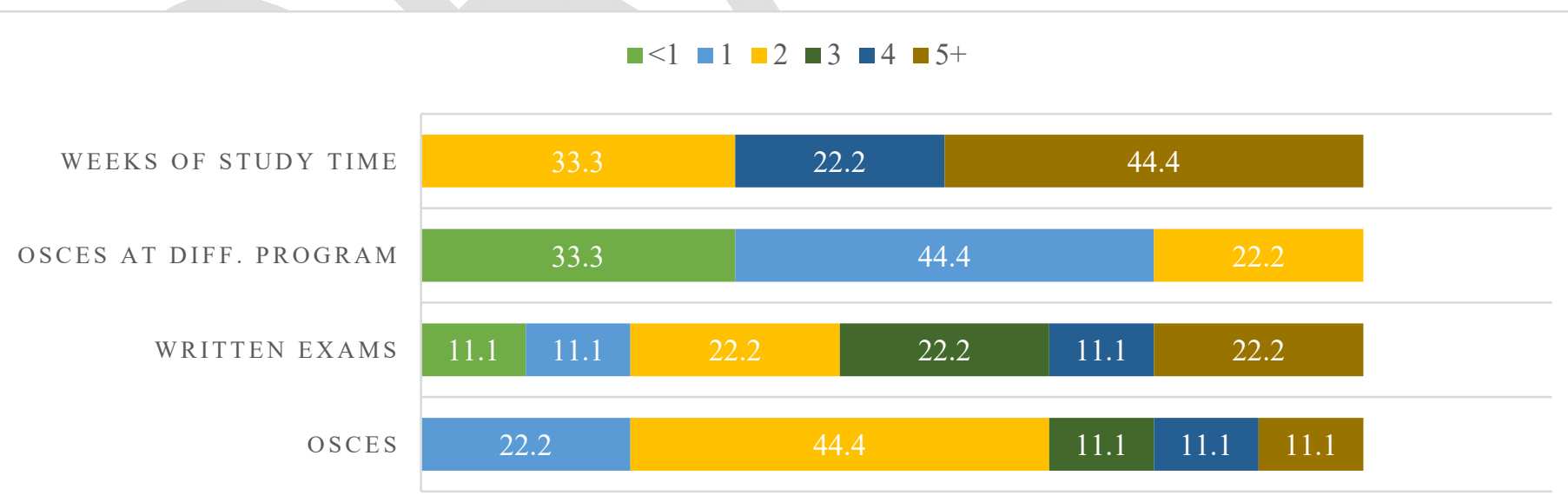


Fig 5. Does your program offer or support residents for X simulation course (\%)?

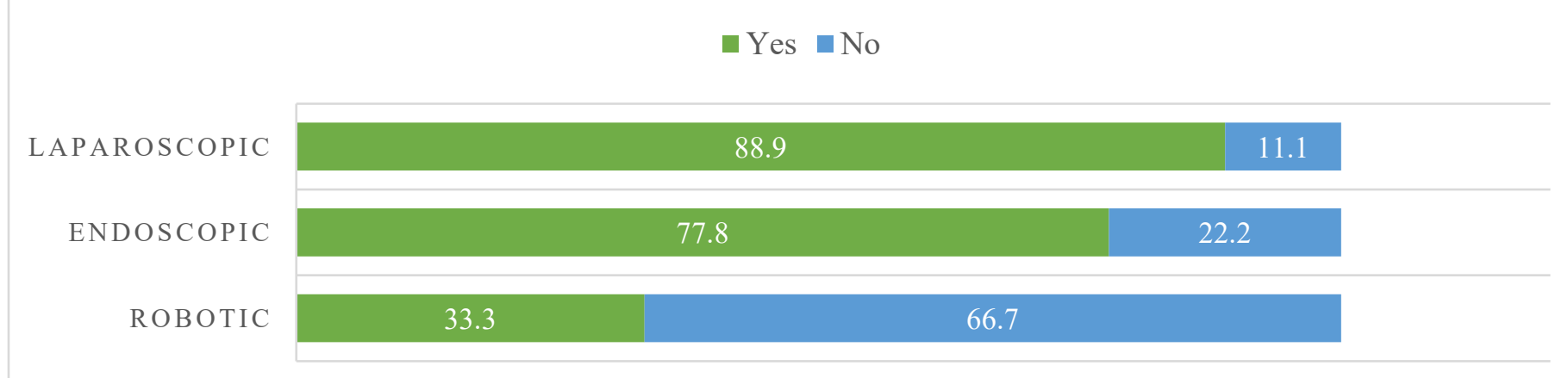

Fig 6. How frequently are simulation courses completed by trainees (\%)?

$\square$ N/A $\square$ Only in PGY1-2 $\square$ Only in PGY3-5 Once per academic year $\square$ Two or more times per academic year

LAPAROSCOPIC

$\begin{array}{llll}11.1 & 11.1 & 33.3 & 44.4\end{array}$

ENDOSCOPIC

11.1

55.6

22.2

ROBOTIC 


\begin{tabular}{|l|c|}
\hline \multicolumn{2}{|l|}{ Table 1. Response rate with geographical information } \\
\hline Region & Response rate (\%) \\
\hline Western ${ }^{*}$ & $3 / 3(100 \%)$ \\
\hline Ontario & $3 / 5(60 \%)$ \\
\hline Quebec & $2 / 3(67 \%)$ \\
\hline Maritime & $1 / 1(100 \%)$ \\
\hline All & $9 / 12(75 \%)$ \\
\hline
\end{tabular}

"British Columbia, Alberta, and Manitoba.

\begin{tabular}{|l|c|c|}
\hline \multicolumn{3}{|c|}{ Table 2. Teaching modalities ranked in terms of importance } \\
\hline Teaching modality & Average rank & Ranges of ranks \\
\hline Campbell's & 1.89 & $(1-5)$ \\
\hline Resident OSCEs & 2.67 & $(1-6)$ \\
\hline Guideline & 3.33 & $(2-6)$ \\
\hline Case presentations & 4.22 & $(2-7)$ \\
\hline Faculty-led & 4.78 & $(1-7)$ \\
\hline Resident-led & 5.00 & $(2-7)$ \\
\hline Simulation labs & 6.11 & $(5-7)$ \\
\hline
\end{tabular}




\section{Appendix 1. Questionnaire}

1. Please select the geographic region for your residency program

Western Canada (BC, Alberta, Manitoba)

Ontario

Quebec

Eastern Canada

2. Please rank the following teaching modalities in terms of importance to resident teaching for preparation of the royal college ( 1 - most important, 7 - least important)
A. Case presentations
B. Resident OSCEs
C. Campbell-Walsh chapter reviews
D. Guideline reviews
E. Simulation labs
F. Resident-led seminars
G. Faculty-led seminars

3. During the academic year, how many days each week are didactic teaching activities scheduled?
A. 1
B. 2
C. 3
D. 4
E. 5

4. In a typical week, the structured resident teaching includes? Select all that apply. Case presentations

\section{Resident OSCEs}

Grand rounds

Campbell-Walsh chapter reviews

Guideline reviews

Simulation labs 
Resident-led seminars

Faculty-led seminars

Other (please specify)

5. In a typical week, how many teaching hours are devoted to

\begin{tabular}{|l|l|l|l|l|l|l|}
\hline & $<1$ & 1 & 2 & 3 & 4 & $5+$ \\
\hline $\begin{array}{l}\text { Campbell- } \\
\text { Walsh } \\
\text { chapter } \\
\text { reviews }\end{array}$ & & & & & & \\
\hline $\begin{array}{l}\text { Guideline } \\
\text { reviews }\end{array}$ & & & & & & \\
\hline $\begin{array}{l}\text { Case } \\
\text { presentations }\end{array}$ & & & & & & \\
\hline $\begin{array}{l}\text { Faculty-led } \\
\text { presentations }\end{array}$ & & & & & & \\
\hline $\begin{array}{l}\text { Resident-led } \\
\text { presentations }\end{array}$ & & & & & & \\
\hline $\begin{array}{l}\text { Grand } \\
\text { Rounds }\end{array}$ & & & & & & \\
\hline $\begin{array}{l}\text { Simulation } \\
\text { Labs }\end{array}$ & & & & & & \\
\hline
\end{tabular}

6. To what extent do you agree with the following statements as it relates to resident education and preparation for the Royal College Certifying Exam?

\begin{tabular}{|l|l|l|l|l|l|}
\hline & $\begin{array}{l}\text { Strongly } \\
\text { disagree }\end{array}$ & Disagree & Neutral & Agree & Strongly agree \\
\hline $\begin{array}{l}\text { Campbell-Walsh chapter } \\
\text { reviews are valuable to } \\
\text { resident teaching }\end{array}$ & & & & & \\
\hline $\begin{array}{l}\text { Guideline reviews are } \\
\text { valuable to resident } \\
\text { teaching }\end{array}$ & & & & & \\
\hline
\end{tabular}




\begin{tabular}{|l|l|l|l|l|l|}
\hline $\begin{array}{l}\text { Case presentations are } \\
\text { valuable to resident }\end{array}$ & & & & \\
teaching & & & & & \\
\hline $\begin{array}{l}\text { Faculty-led presentations } \\
\text { are valuable to resident } \\
\text { teaching }\end{array}$ & & & & & \\
\hline Resident-led & & & & \\
presentations are & & & & \\
valuable to resident & & & & \\
teaching & & & & \\
\hline $\begin{array}{l}\text { Grand Rounds are } \\
\text { valuable to resident } \\
\text { teaching }\end{array}$ & & & & & \\
\hline Simulation Labs are & & & & \\
valuable to resident & & & & \\
teaching & & & & \\
\hline
\end{tabular}

7. In a typical academic year:

\begin{tabular}{|c|c|c|c|c|c|c|}
\hline \multirow{2}{*}{$\begin{array}{l}\text { How many times does your } \\
\text { program evaluate residents } \\
\text { with formal OSCEs? }\end{array}$} & $<1$ & 1 & 2 & 3 & 4 & $5+$ \\
\hline & & & & & & \\
\hline $\begin{array}{l}\text { How many times does your } \\
\text { program evaluate residents } \\
\text { with written exams (e.g. } \\
\text { short answer or multiple- } \\
\text { choice)? }\end{array}$ & & & & & & \\
\hline $\begin{array}{l}\text { How many times do you send } \\
\text { your trainees to another } \\
\text { program for OSCE } \\
\text { exams? (Excluding QUEST) }\end{array}$ & & & & & & \\
\hline $\begin{array}{l}\text { How many weeks of } \\
\text { "protected study time" is }\end{array}$ & & & & & & \\
\hline
\end{tabular}


given to Chief residents prior

to their Royal College exam?

8. Does your program offer or support residents for

\begin{tabular}{|l|l|l|}
\hline & No & Yes \\
\hline a robotic simulation course? & & \\
\hline an endoscopic simulation course? & & \\
\hline a laparoscopic simulation course? & & \\
\hline
\end{tabular}

9. How frequently are simulation courses completed by trainees?

\begin{tabular}{|l|l|l|l|l|l|}
\hline & N/A & $\begin{array}{l}\text { Once per } \\
\text { academic } \\
\text { year }\end{array}$ & $\begin{array}{l}\text { Two or } \\
\text { more times } \\
\text { per year }\end{array}$ & $\begin{array}{l}\text { In senior } \\
\text { years } \\
\text { only } \\
\text { (PGY3- } \\
5)\end{array}$ & $\begin{array}{l}\text { In junior } \\
\text { years only } \\
\text { (PGY1-2) }\end{array}$ \\
\hline Robotic simulation & & & & & \\
\hline Endoscopic simulation & & & & & \\
\hline Laparoscopic simulation & & & & & \\
\hline
\end{tabular}

10. Is your program changing the academic curriculum based on the implementation of Competency-By-Design (CBD)?

No

Yes (please explain briefly) 